\title{
Endovascular aortic stent graft placement to exclude the left ventricular assist device outflow graft on the descending aorta during heart transplant
}

\author{
Jérôme Jouan, MD, Jean-Marc Alsac, MD, PhD, Alain Bel, MD, and \\ Jean-Michel Grinda, MD, Paris, France
}

\footnotetext{
From the Department of Cardiovascular Surgery, Assistance Publique Hôpitaux de Paris, Hôpital Européen Georges Pompidou, Paris, France; and University Paris-Descartes, Sorbonne Paris Cité, Paris, France.

Disclosures: J.M. Alsac has recieved proctorship fees from Gore France. All other authors have nothing to disclose.

Received for publication Aug 31, 2018; revisions received Nov 7, 2018; accepted for publication Nov 18, 2018; available ahead of print Jan 11, 2019.

Address for reprints: Jérôme Jouan, MD, Department of Cardiovascular Surgery, Hôpital Européen Georges Pompidou, 20 rue Leblanc, 75809 Paris, France (E-mail: jouanjerome@ hotmail.com).

J Thorac Cardiovasc Surg 2019;157:e387-9

$0022-5223 / \$ 36.00$

Copyright (C) 2018 by The American Association for Thoracic Surgery

https://doi.org/10.1016/j.jtcvs.2018.11.096
}

Video clip is available online.

Alternative approaches to a median sternotomy have been proposed for left ventricular assist device (LVAD) implantation, with excellent results. ${ }^{1}$ An exclusive left lateral thoracotomy approach involves a distal outflow graft (OG) anastomosis to the descending aorta. Potential advantages consist of preservation of right ventricular function and reduction in postoperative bleeding. A further advantage includes the avoidance of resternotomy, which can be beneficial if coronary artery bypass grafting has previously been performed or for a subsequent heart transplant (HTx). At the time of device explantation, however, dissection in the left pleural cavity to control the OG before inducing cardiopulmonary bypass could be challenging. We describe the placement of an endovascular aortic stent graft as a simple method to exclude the OG intraoperatively during HTx in a recipient who had previously undergone implantation with an LVAD through a left thoracotomy.

\section{CASE REPORT}

A 56-year-old man underwent HTx for ischemic endstage cardiomyopathy. His surgical background consisted of previous coronary artery bypass grafting for triplevessel disease; placement of an implantable cardiac defibrillator; and, more recently, implantation of a HeartWare LVAD (HVAD; Medtronic, Minneapolis, Minn) through a left lateral thoracotomy. This approach involved distal anastomosis of the OG to the descending aorta a few centimeters below the origin of the left subclavian artery.

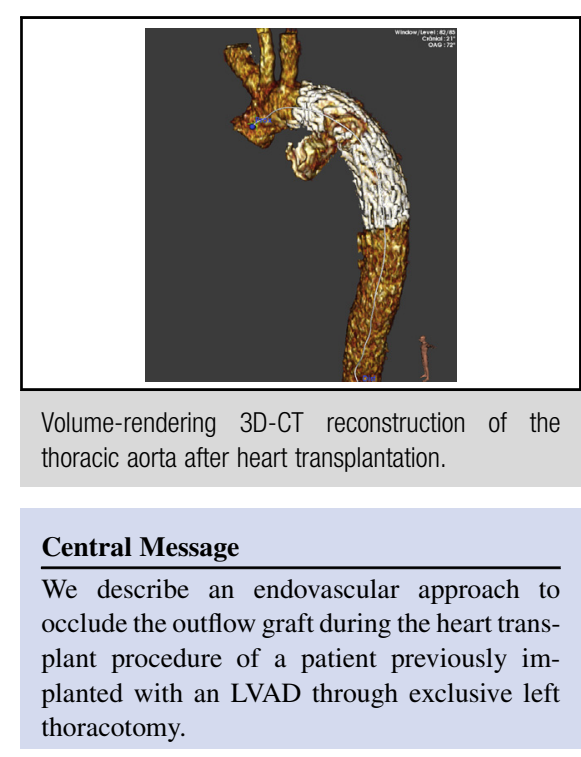

See Commentary on page e391.

After initiation of peripheral cardiopulmonary bypass through left groin cannulation, the right femoral artery was punctured to introduce a $100-\mathrm{mm}$ Gore C-TAG endograft (W.L. Gore and Associates, Flagstaff, Ariz), which was positioned in the descending aorta in front of the HeartWare OG band relief under x-ray fluoroscopy. Before complete deployment of the endoprosthesis, the LVAD was stopped. The endograft was positioned distal to the origin of the left subclavian artery and proximal to the predicted origin of the artery of Adamkiewicz (Figure 1). Median resternotomy was then performed. After explantation of the recipient heart, the HeartWare OG was transected inside the pericardium where convenient, and the pump was easily removed. The OG remnant was further dissected and resected. The proximal portion was oversewn, and its remnant was left abandoned in the left pleural cavity (Figure 2, Figure 3, and Video 1). The HTx procedure was then conducted in standard fashion. Nine months later, the patient is doing well with no exertional symptoms. No neurologic or infectious complications related to retained $\mathrm{OG}$ material were noted. His latest echocardiogram showed normal ventricular function. 


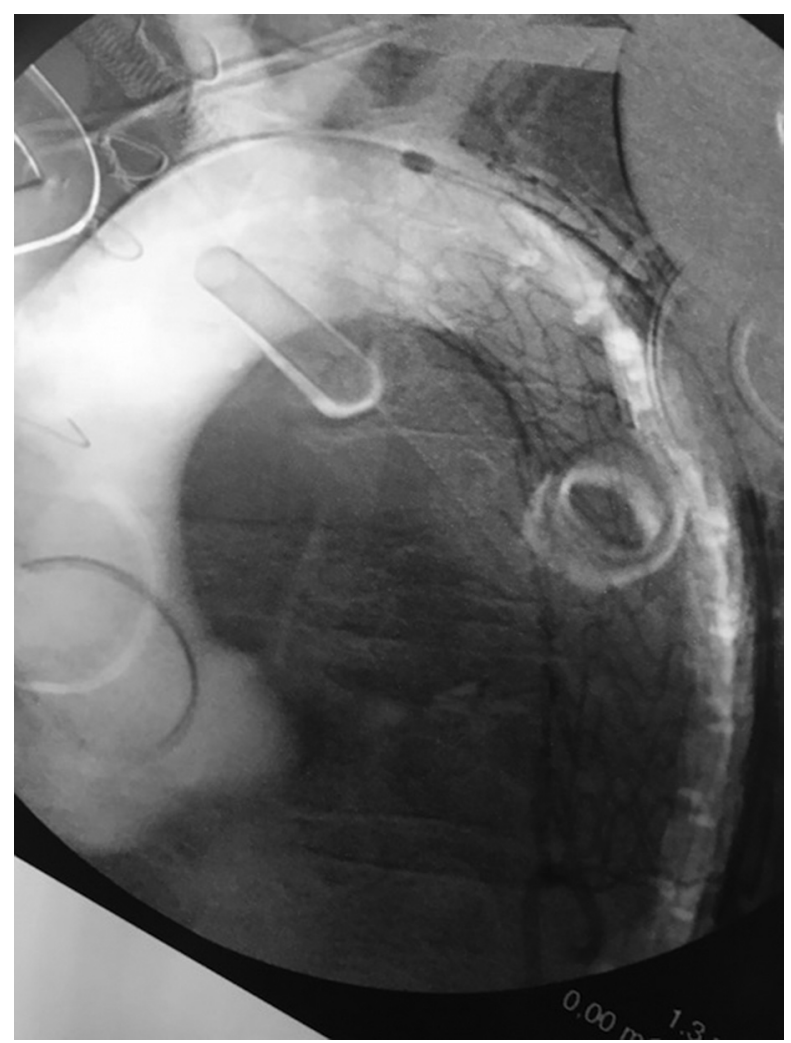

FIGURE 1. Intraoperative aortography of stent-graft deployment next to the HeartWare (HVAD; Medtronic, Minneapolis, Minn) outflow graft bend relief. Adequate positioning is confirmed by the absence of left subclavian obstruction and retrograde outflow graft filling.

\section{DISCUSSION}

Mild excess postoperative mortality is still reported after HTx in LVAD recipients. ${ }^{2}$ Longer and more complicated reoperations as a result of dense adhesions and potential damage to the OG or drive line are possible contributors. Indeed, the initial step of recipient heart removal consists of the control and the external ligation of the OG to avoid torrential arterial flow from the descending aorta through the LVAD and subsequent hemodynamic compromise. In this case, division of adhesions that could give access to the external aspect of the OG was complicated by the presence of patent coronary grafts, a fixed apical ventricular segment connected to the intrapericardial device, and a short intrapericardial OG path. Although we concede that the durability and risk for potential infection of aortic stent grafts in an immunosuppressed patient remains unknown, our method for endovascular occlusion of the OG distal anastomosis presents the advantage of allowing fast and safe removal of the recipient heart with limited dissection of its anterior aspect.

Three major concerns could arise after leaving a small blind limb of Dacron polyester fabric graft inside the pleural cavity: infection, embolism, and pseudoaneurysm at the level of OG distal anastomosis. To limit further the risk of infection, we minimized the length of OG retention limb left in the pleura. One could argue that even a small graft remnant could become a source for complications; clinically, however, this threat seems to be more theoretic than practical. An analysis by Baldwin and colleagues ${ }^{3}$ demonstrated that in a series of 27 patients who were weaned from LVAD support by 4 different methods (from complete pump explantation to simple drive line transection), there was no significant difference in terms of long-term neurologic or infectious adverse sequelae regardless of the LVAD portion that remained in situ. Cohn and associates ${ }^{4}$ also reported no complications related to OG remnants in a series of 18 patients who underwent HTx after LVAD implantation between the left ventricular apex and the
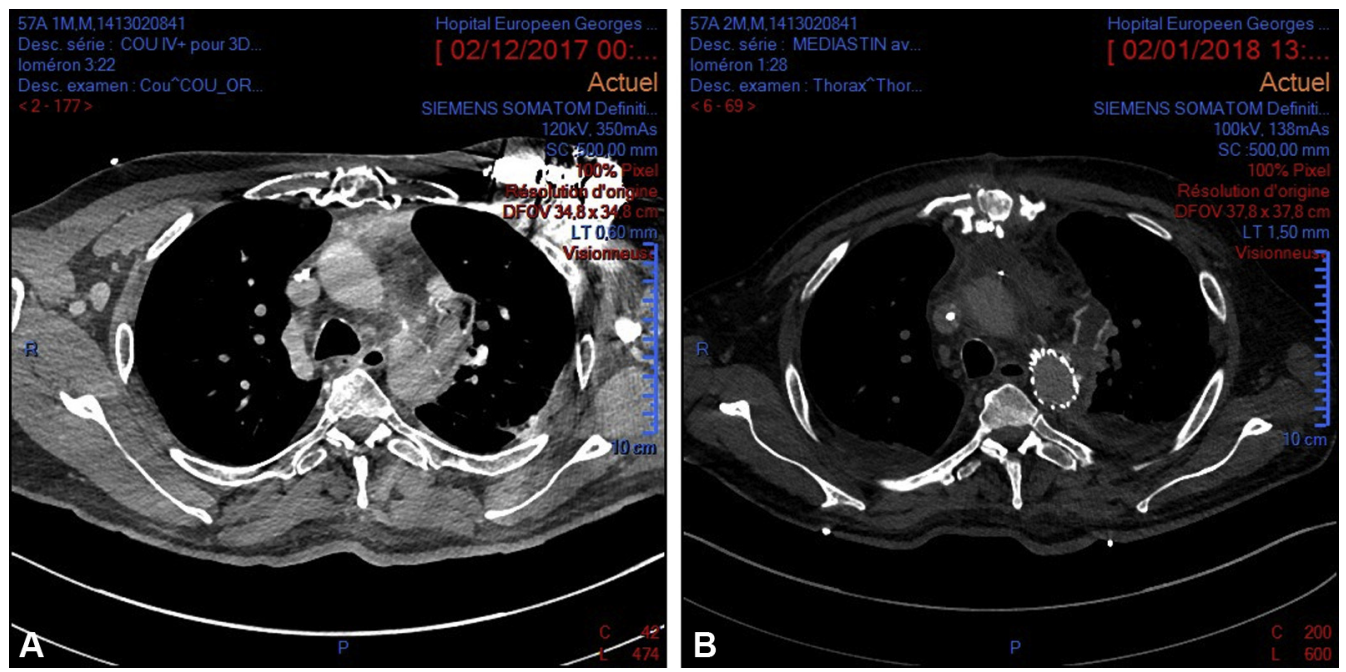

FIGURE 2. Preoperative (A) and postoperative (B) angiographic computed tomographic scan showing the device outflow graft distal anastomosis area. The retained portion of the outflow graft can be seen adjacent to the descending aorta. 


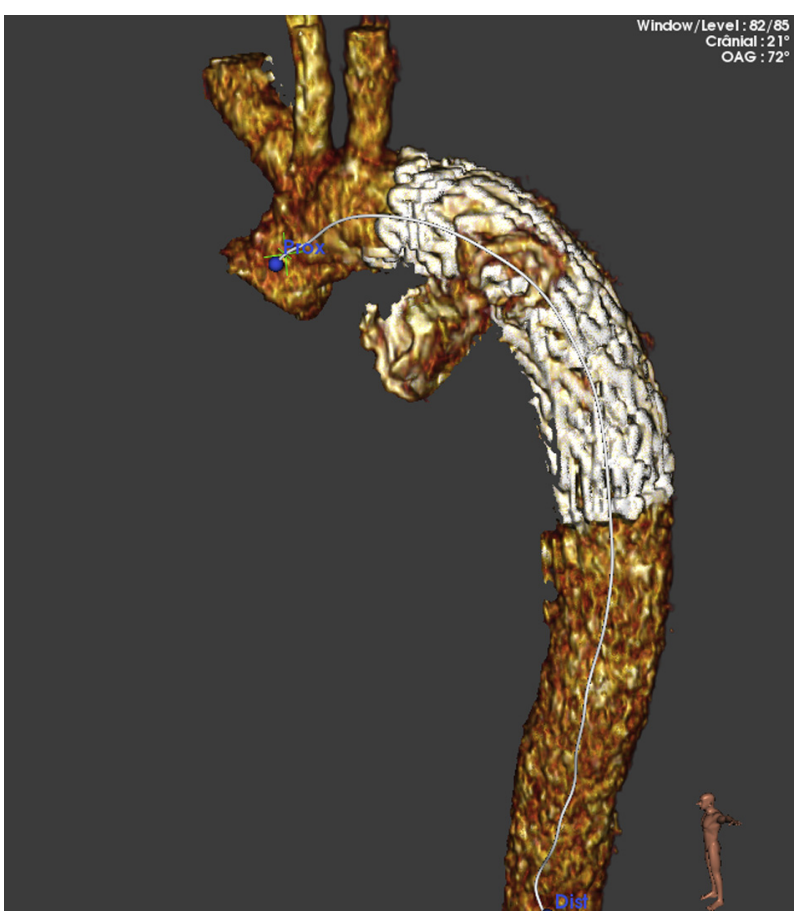

FIGURE 3. Postoperative 3-dimensional computed tomographic imaging volume-rendering reconstruction of the descending aorta showing the position of the aortic stent graft in relation to the outflow graft remnant.

supraceliac aorta. Our method of intra-aortic endovascular LVAD distal anastomosis occlusion also has the advantage relative to external ligation in terms of avoiding potential distal emboli from clots in the blind OG limb and pseudoaneurysm formation.

For the prevention of spinal cord injury during aortic stent-graft implantation, the European Society for Vascular Surgery recommends limitation in the coverage of the descending aorta to less than $200 \mathrm{~mm}$, avoidance of the T8 to T12 levels, and exclusion of the left subclavian artery ostium. $^{5}$ In our case, all these precautions were applied, facilitated by initial adequate positioning of the distal OG anastomosis at the time of LVAD implantation.

\section{CONCLUSIONS}

At the time of HTx, endovascular occlusion of the OG anastomosis in the descending aorta is a simple method to allow safe explantation of an LVAD inserted through an

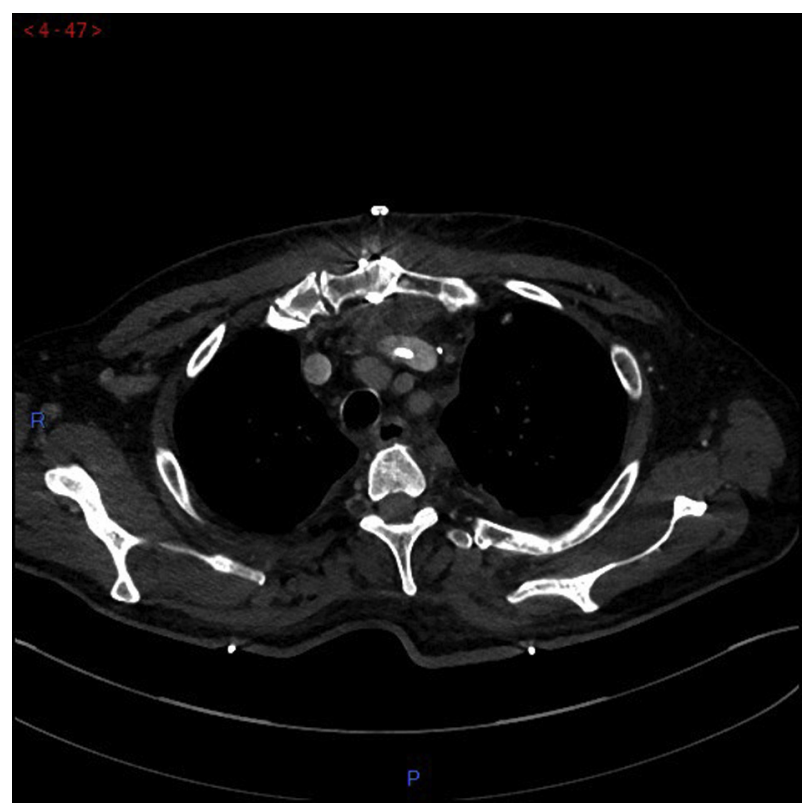

VIDEO 1. Video showing the entire acquisition of the postoperative computed tomographic angiographic scan. Video available at: https:// www.jtcvs.org/article/S0022-5223(18)33242-2/fulltext.

exclusive left lateral thoracotomy. This approach limits extensive and hazardous dissection and could further prevent neurologic, mechanical, or infectious complications related to the retained OG limb adjacent to the aorta.

We thank Dr Yashutosh Joshi, MBBS, for his editing contribution.

\section{References}

1. Ozbaran M, Yagdi T, Engin C, Nalbantgil S, Ozturk P. Left ventricular assist device implantation with left lateral thoracotomy with anastomosis to the descending aorta. Interact Cardiovasc Thorac Surg. 2018;27:186-90.

2. Donneyong M, Cheng A, Trivedi JR, Schumer E, McCants KC, Birks EJ, et al. The association of pretransplant HeartMate II left ventricular assist device placement and heart transplantation mortality. ASAIO J. 2014;60:294-9.

3. Baldwin ACW, Sandoval E, Letsou GV, Mallidi HR, Cohn WE, Frazier OH. Surgical approach to continuous-flow left ventricular assist device explantation: a comparison of outcomes. J Thorac Cardiovasc Surg. 2016;151:192-8.

4. Cohn WE, Fikfak V, Gregoric ID, Frazier OH. Retention of left ventricular assist device outflow grafts after transplantation. J Heart Lung Transplant. 2008;27: 865-8.

5. Riambau V, Böckler D, Brunkwall J, Cao P, Chiesa R, Coppi G, et al. Editor's choice-management of descending thoracic aorta diseases: clinical practice guidelines of the European Society for Vascular Surgery (ESVS). Eur J Vasc Endovasc Surg. 2017;53:4-52. 